\title{
Thoracoscopy: general overview and place in the diagnosis and management of pleural effusion
}

\author{
F. Rodriguez-Panadero*, J.P. Janssen" and P. Astoul ${ }^{*}$
}

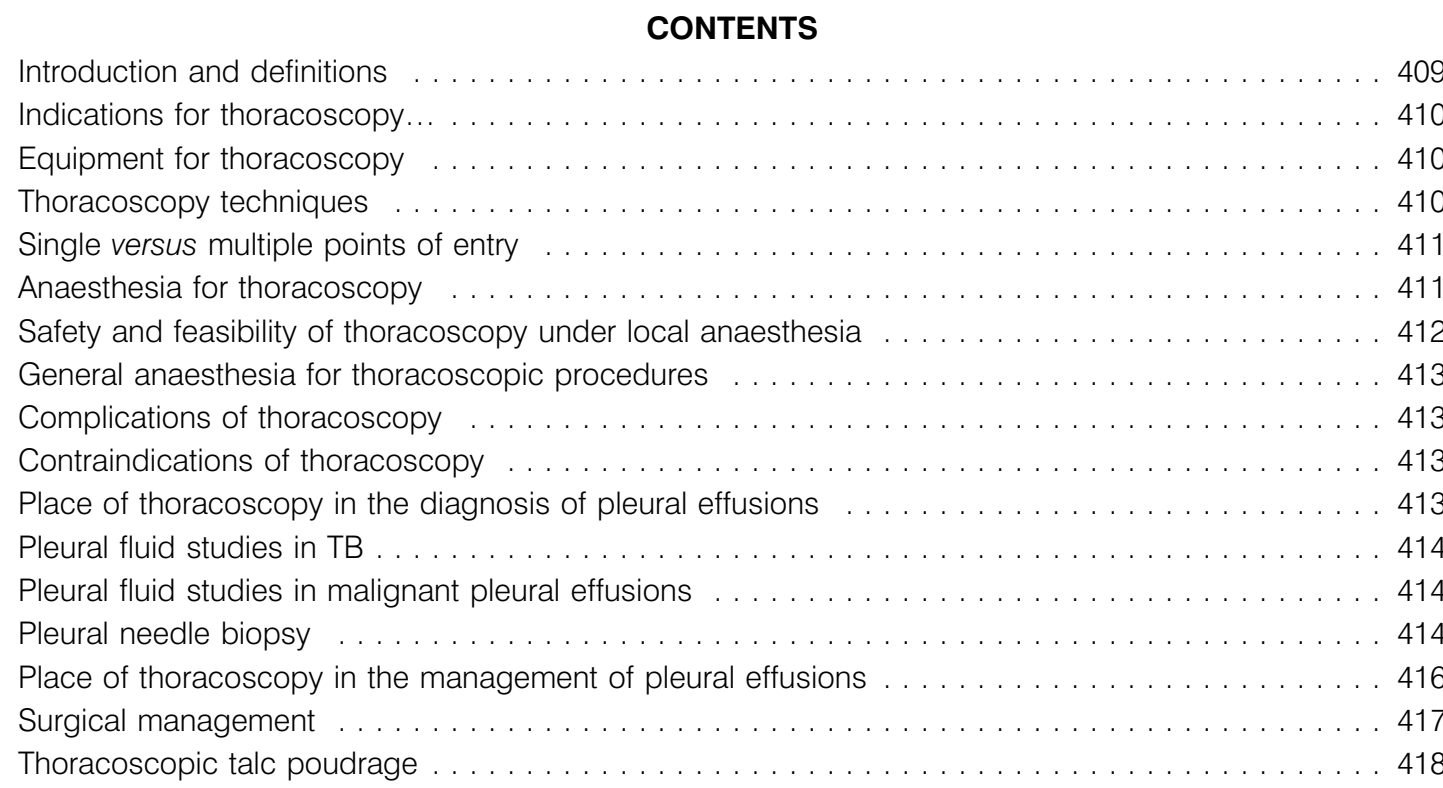

KEYWORDS: Pleural disease, pleural effusion, thoracoscopy

\section{INTRODUCTION AND DEFINITIONS}

Thoracoscopy is not a new technique; H.C. Jacobeus, the Swedish internist, was the first to perform thoracoscopy in 1910, as a diagnostic procedure for exudative pleuritis [1]. H.C. Jacobeus published the first series of thoracoscopy cases in 1921, describing the value of thoracoscopy in the diagnosis of tuberculous and malignant effusions. However, in the following decades, thoracoscopy was used mainly as a therapeutic tool for adhesiolysis in patients with tuberculosis (TB), in order to obtain a "therapeutic" pneumothorax. After the decline of thoracoscopic interventions as a treatment for $\mathrm{TB}$, some centres in continental Europe continued to use thoracoscopy as a diagnostic and therapeutic tool in other disorders, such as pneumothorax and pleural effusion. Pioneers like SwIERENGA et al. [2], BRANDT [3] and BOUTIN et al. [4] confirmed its value in publications in the 1970s. In the UK and the USA, thoracoscopy was not a widespread procedure, and open thoracotomy was the preferred procedure to obtain a diagnosis in pleuropulmonary disease.

Around 1990, instruments such as endoscopic stapler devices, scissors, grasping and biopsy forceps were developed for surgical interventions by means of thoracoscopy in the thorax. The development of endoscopic video systems and

Previous articles in this series: No. 1: Bolliger CT, Sutedja TG, Strausz J and Freitag L. Therapeutic bronchoscopy with immediate effect: laser, electrocautery, argon plasma coagulation and stents. Eur Respir J 2006; 27: 1258-1271. No. 2: Vergnon J-M, Huber RM and Moghissi K. Place of cryotherapy, brachytherapy and photodynamic therapy in therapeutic bronchoscopy of lung cancers. Eur Respir J 2006; 28: 200-218.

AFFILIATIONS

*Unidad Médico-Quirúrgica de Enfermedades Respiratorias, Hospital Universitario Virgen del Rocío, Sevilla, Spain

\#Dept of Pulmonology, Canisius Wilhelmina Hospital, Nijmegen, The Netherlands.

'Dept of Pulmonary Diseases, Division of Thoracic Oncology, SteMarguerite Hospital, University of The Mediterranean, Marseille, France.

\section{CORRESPONDENCE}

F. Rodriguez-Panadero

El Mirador

P. $13-1^{\circ} \mathrm{B}$

41940 Tomares: Sevilla

Spain

Fax: 34955013292

E-mail: frpanad@supercable.es

Received

January 302006

Accepted:

May 032006

\section{SUPPORT STATEMENT}

Part of the work mentioned in this article from one of the authors (F.R Panadero) was supported by Red RESPIRA 03/11, I.S. Carlos III, Spain. 
instrumentation lead to the widespread use, by (thoracic) surgeons, of therapeutic thoracoscopy for a wide variety of major thoracic procedures (video-assisted thoracic surgery; VATS). However, the present article does not deal with VATS itself, but with the thoracoscopic procedure that was performed by pulmonologists for many decades and subsequently became referred to as "medical thoracoscopy".

Medical thoracoscopy is generally characterised as thoracoscopy performed under local anaesthesia in the endoscopy suite with the use of nondisposable instruments, and is generally for diagnostic purposes. In contrast, VATS is described as a keyhole surgical procedure in the operating room, under general anaesthesia with one-lung ventilation using disposable instruments, generally for therapeutic purposes. However, the current authors do not support the term "medical thoracoscopy". Thoracoscopy is always an invasive procedure, and the word "medical" is, in the current authors' opinion, therefore not appropriate. Moreover, pulmonologists may perform thoracoscopy for diagnostic as well as therapeutic goals under local or general anaesthesia [5-8].

\section{INDICATIONS FOR THORACOSCOPY}

Thoracoscopy can be performed for diagnostic as well as therapeutic purposes. The most frequent indication for diagnostic thoracoscopy is pleural effusion. Thoracoscopy in spontaneous pneumothorax may identify the cause of the pneumothorax. The most frequent indication for therapeutic thoracoscopy is pleurodesis (mostly chemical) to prevent recurrence of pleural effusion. Indications for diagnostic and therapeutic thoracoscopy are summarised in table 1, and are discussed in more detail in the current paper and in other review articles in this series.

\section{EQUIPMENT FOR THORACOSCOPY}

The standard equipment for thoracoscopy consists of a trocar, an obturator, an optical telescope, a light source and biopsy forceps (either optical or not; fig. 1).

The optimal diameter of the thoracoscope (trocar and telescope) is $7 \mathrm{~mm}$, like the standard equipment for thoracoscopy as developed by Boutin (Wolf Company, Knittlingen, Germany). Larger telescopes (diameter 10-12 mm) are often used by surgeons. These sizes would require careful and extensive application of local anaesthetics, and would therefore be less suitable for thoracoscopy under local anaesthesia,

\begin{tabular}{|c|c|}
\hline $\begin{array}{l}\text { TABLE } 1 \text { Indications fo } \\
\text { anaesthesia }\end{array}$ & $\begin{array}{l}\text { racoscopy and preferred } \\
\text { ifferent indications }\end{array}$ \\
\hline Local anaesthesia & $\begin{array}{l}\text { Diagnosis of pleural effusion } \\
\text { Pleural biopsy } \\
\text { Spontaneous pneumothorax }\end{array}$ \\
\hline Local or general anaesthesia & $\begin{array}{l}\text { Empyema (early stage) } \\
\text { Bullectomy } \\
\text { Chemical pleurodesis } \\
\text { Pulmonary biopsy (forceps) }\end{array}$ \\
\hline General anaesthesia & $\begin{array}{l}\text { Sympatholysis } \\
\text { Empyema (chronic stage) } \\
\text { Pulmonary biopsy (stapler) }\end{array}$ \\
\hline
\end{tabular}

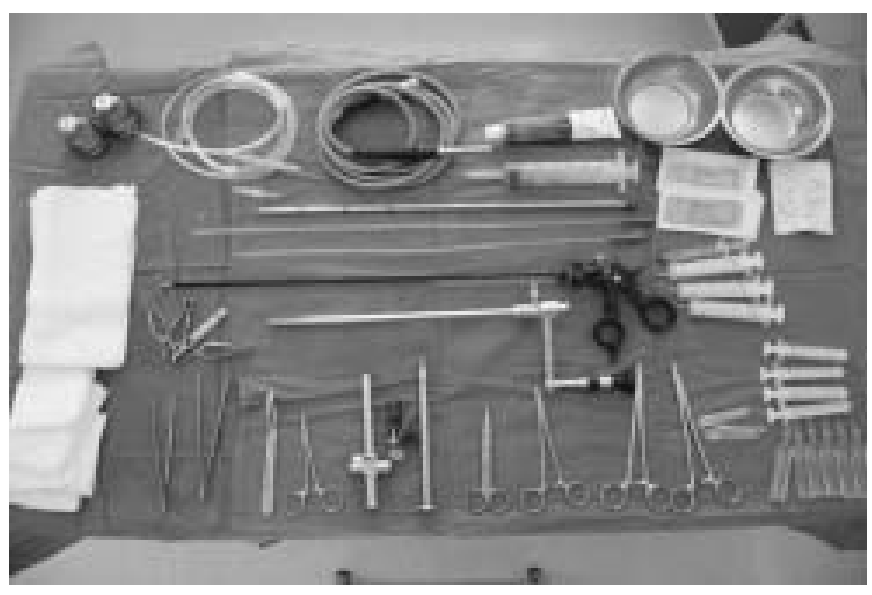

FIGURE 1. Standard equipment for thoracoscopy in pleural effusions.

because manipulation of a telescope of this size in the intercostal space is painful. There may be a place for equipment with a smaller diameter, the so-called minithoracoscopy (see the Alternative equipment section). The 5-mm optical biopsy forceps provide large adequate biopsies; diagnostic superiority compared with the 3-mm forceps has not yet been proven [9].

\section{Alternative equipment for thoracoscopy}

Several alternative instruments were used for thoracoscopy. A flexible bronchoscope has been used for thoracoscopy [10, 11], and, more recently, a dedicated semi-rigid thoracoscope was developed [12]. Compared with rigid instruments, the control of the working end of the flexible thoroscope is limited due to its flexibility. The biopsy size is small $(2 \mathrm{~mm})$, which may limit the diagnostic yield, especially in the case of mesothelioma. The size of the trocar is the same as for rigid equipment, which means that the discomfort for the patient during the procedure is not reduced. The use of the flexible and the semi-rigid equipment has the disadvantage of flexible instruments including: reduced manoeuvrability, high costs, vulnerability, difficulty in sterilisation and small size of the biopsies. There are no clear advantages of flexible over rigid thoracoscopy equipment.

Recently, minithoracoscopy was developed as an alternative for diagnostic thoracoscopy under local anaesthesia. A minithoracoscopy set consists of rigid equipment with smaller sizes than standard equipment. In a recent study, TASSI et al. [13] used a 3-mm thoracoscope for diagnostic thoracoscopy under local anaesthesia. The diagnostic yield in that study was $93 \%$. JANSSEN et al. [14] compared minithoracoscopy using the 3-mm and the 2-mm sets with standard thoracoscopy using the 7-mm set. The diagnostic yield of the 3-mm set was $100 \%$, the same as for the 7-mm set. The yield of diagnostic biopsies using the 2mm set was only $40 \%$. It is always necessary to create a second port of entry when taking biopsies with the minithoracoscope, in contrast to the standard equipment.

\section{THORACOSCOPY TECHNIQUES}

The patient is positioned in the lateral decubitus position, with normal lung in the dependent position. Details about patient positioning have been described in detail in several 
publications $[4,15]$. The optimal point of entry depends on the patient's suspected disease; for pneumothorax a higher point of entry is chosen (third or fourth intercostal space), as most abnormalities in this disease (blebs and bullae) can be found at the apex of the lung and can best be visualised from a high point of entry. In case of suspected malignancy, a lower point of entry is preferred (sixth or seventh intercostal space), as most pleural malignancies are expected to be found in the lower area of the pleura [16]. The optimal point of entry is localised in the midaxillary line, because there are no large muscles to be passed by the trocar in this area.

Some authors advise the creation of a pneumothorax a few hours or even the day before the thoracoscopy. This technique may reduce blood flow in the periphery of the lung, and may prevent damage to the lung after introduction of thoracoscopy instruments [4]. In the current authors' experience, direct introduction of a blunt trocar into the thoracic wall, without prior induction of a pneumothorax, is safe and effective (fig. 2).Very occasionally, introduction of the trocar can be troublesome in the case of pleural adhesions. Therefore, introduction of the trocar must be performed slowly and carefully. The inner part of the trocar must be withdrawn when a reduction of resistance is felt, after passage of the parietal pleura.

At the point of entry, $15-30 \mathrm{~mL}$ of lidocaine $1 \%$ or mepivacaine is injected perpendicular to the skin, at the level of skin, subcutis, intercostal muscles and the parietal pleura. When simultaneous heavy sedation is applied, $15 \mathrm{~mL}$ of lidocaine is used; $30 \mathrm{~mL}$ is often used with light sedation. Addition of adrenalin may reduce the amount of blood oozing from the
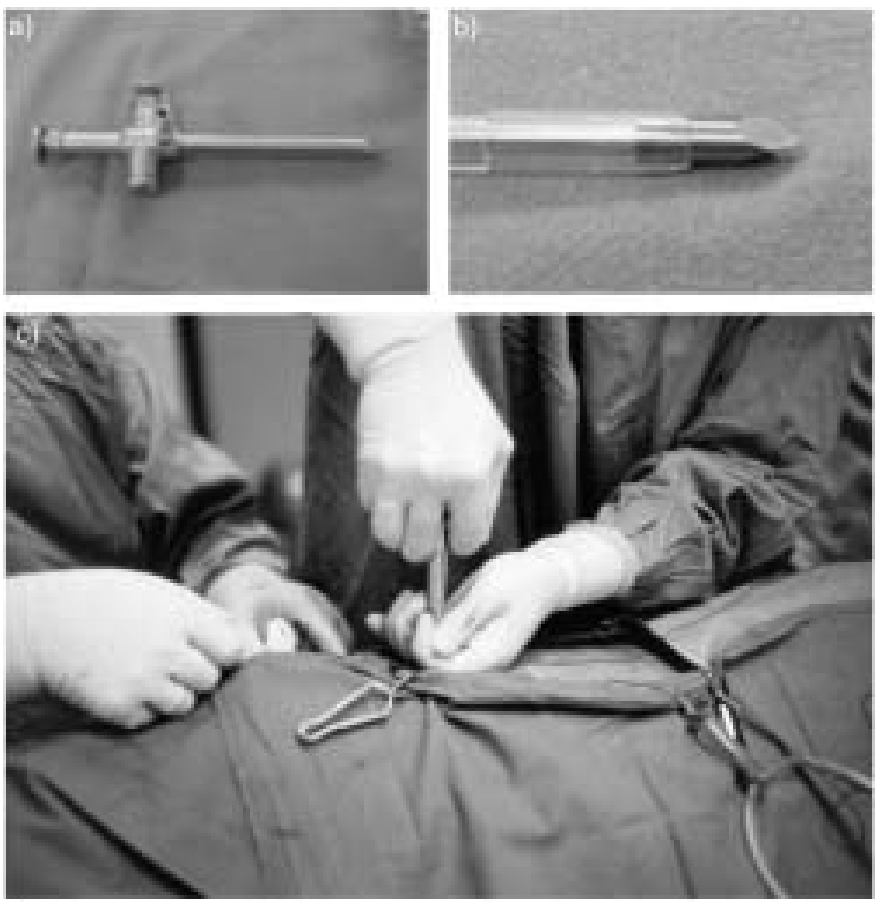

FIGURE 2. a) Preferred trocar for thoracoscopy with conical tip. b) The triangular tip can provoke damage to the intercostal vessels. c) Introduction of the trocar in the pleural cavity. Care must be taken in controlling the pressure applied when using the left hand as a "brake". intercostals or pleural vessels, thus minimising contamination of the optical telescope by blood [4, 17].

After passage of the trocar through the parietal pleura and removal of the obturator, the pleural cavity will be exposed to the atmospheric pressure. As a consequence of unopposed elastic recoil, the lung will collapse, resulting in paradoxical respiration. During inspiration the upper lung will collapse, which causes entry of air through the trocar. The thoracoscopist can use this phenomenon to enlarge the collapse of the lung in order to improve the visualisation of the pleural space and the lung surface. During inspiration, the trocar is open and air can enter the pleural space. The spontaneously breathing patient may have impaired gas exchange as a result of paradoxical respiration and mediastinal shift. It is therefore important to administer supplementary oxygen and to keep the procedure short and simple.

\section{SINGLE VERSUS MULTIPLE POINTS OF ENTRY}

From the patient's viewpoint, the single entry technique for thoracoscopy is preferred, especially under local anaesthesia. Discomfort due to pain and stitches is limited to a single incision of $1.5 \mathrm{~cm}$, which is the same as for chest tube insertion. Most cases of diagnostic thoracoscopy can be performed with a single port of entry. After inspection of the pleura, the optical telescope is replaced by the optical biopsy forceps, consisting of forceps with an attached telescope, which allows the thoracoscopist to take biopsies under direct visual control. Another alternative would be using the so-called "operative thoracoscope" (the "bayonet" thoracoscope; fig. 3), which allows large biopsies to be taken under visual control with a single port of entry. Recently, smaller thoracoscopes intended to perform biopsy under direct visual control have been developed (fig. 4).

In the double-entry technique, the optical telescope is not removed, but a second port of entry is created under visual control. Biopsy forceps are introduced through a second (smaller) trocar (fig. 5). The advantage of the double-entry technique is a better view when biopsies are taken, and the possibility to obtain biopsies with electrocautery sealing, which is of advantage when biopsies are taken of the visceral pleura.

\section{ANAESTHESIA FOR THORACOSCOPY}

The pre-operative evaluation of the patient includes spirometry, electrocardiogram (ECG), blood gas analysis and routine blood chemistry analysis.

Pre-operative preparation may involve chest physiotherapy, bronchodilators, antibiotics and corticosteroids to optimise pulmonary function in patients with obstructive lung disease. Current medications should generally be continued. Benzodiazepines are commonly used to produce anxiolysis and sedation. The role of pre-operative medication has not been subjected to randomised study; some authors routinely administer $0.4-0.8 \mathrm{mg}$ of atropine s.c. prior to the procedure, to prevent vasovagal reactions [15], either with or without midazolam (5 mg) [4]. Sedation during the procedure is performed using incremental dosages of a narcotic (morphine or fentanyl) and a benzodiazepine. Agents to antagonise both morphine and benzodiazepine should be available [15]. 

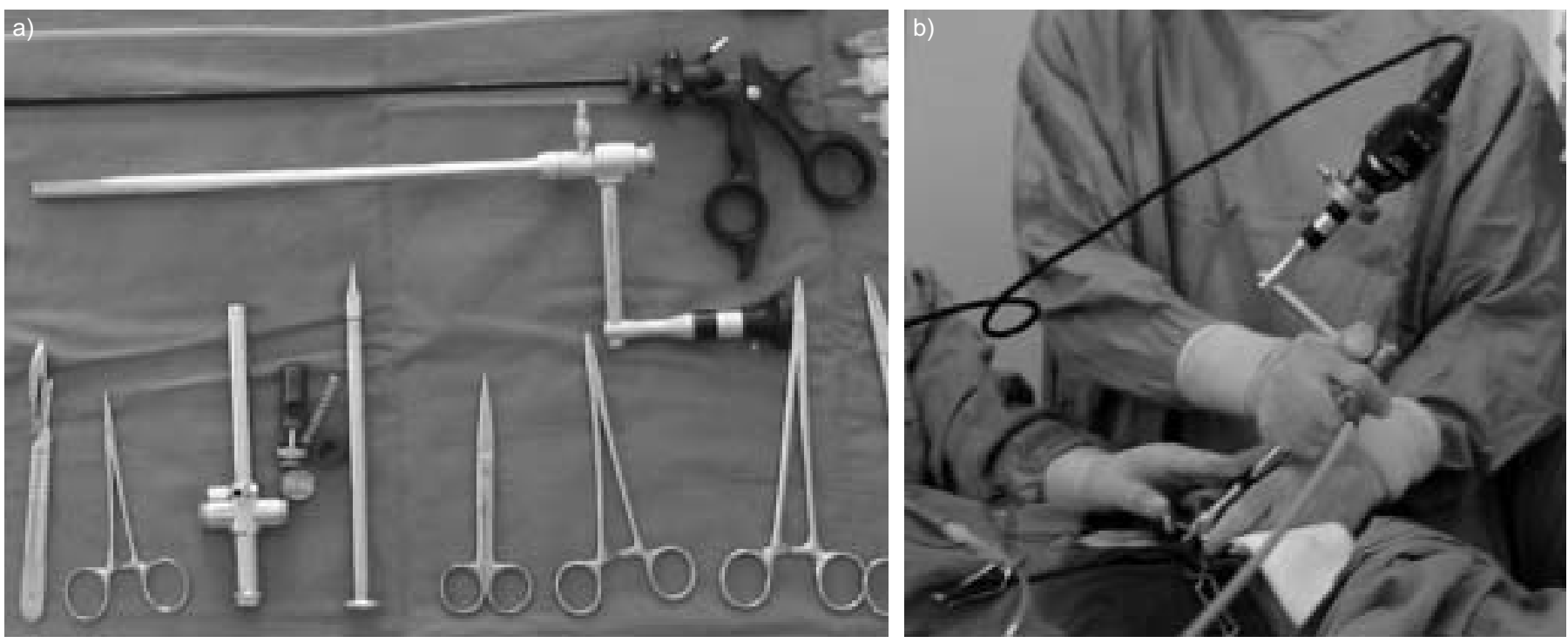

FIGURE 3. "Bayonet" thoracoscope (a) and in use (b), which allows large biopsies to be taken with a single port of entry.

Patients should have an intravenous cannula. Basic monitoring includes ECG and pulse oximetry, and supplementary oxygen should be provided to the patient to maintain oxygen saturation $>90 \%$.

International normalised ratio (INR) should be $<2.0$ to ensure a biopsy is taken safely in patients using anticoagulant medication. Use of aspirin may prolong bleeding time, but is not an absolute contraindication to taking biopsies.

\section{SAFETY AND FEASIBILITY OF THORACOSCOPY UNDER LOCAL ANAESTHESIA}

In the surgical literature, thoracoscopy procedures are often performed under general anaesthesia with double lumen intubation [18]. However, most diagnostic procedures can be performed under local anaesthesia, as has been confirmed by many authors $[4,6,19-21]$. Some centres use local anaesthesia with "conscious sedation". This term is widely used in the literature, and refers to patients who remain awake or arousable during the procedure, while given mild anxiolytics and pain medications.

Some centres described thoracoscopic procedures under local anaesthesia and intravenous sedation [22, 23]; in these

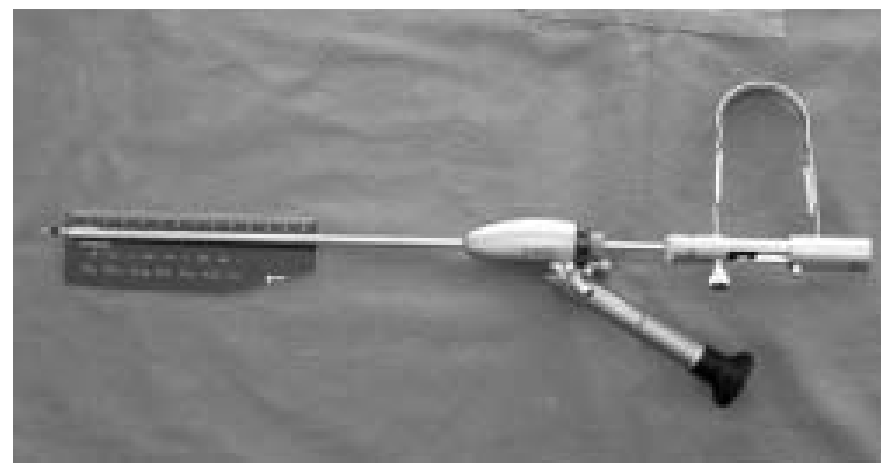

FIGURE 4. Biopsy forceps combined with a small scope for single-entry thoracoscopy. studies, sedation was obtained by intravenous administration of propofol and fentanyl. This technique requires the permanent assistance of an anaesthetist in many countries. In this article, thoracoscopy under local anaesthesia is defined as a procedure without the help or the assistance of an anaesthetist.

There is no consensus in the literature on the appropriateness of performing thoracoscopy under local anaesthesia [18, 19]. Considerations which may help in choosing the most suitable anaesthetic technique for thoracoscopy include the following. 1) The mental status of the patient, those afraid of any medical procedure should be offered general anaesthesia. Children and patients with learning difficulties should be treated under general anaesthesia in all circumstances. 2) The suspected duration and type of thoracoscopy; when a procedure is suspected to be long or painful, e.g. multiloculated empyema,

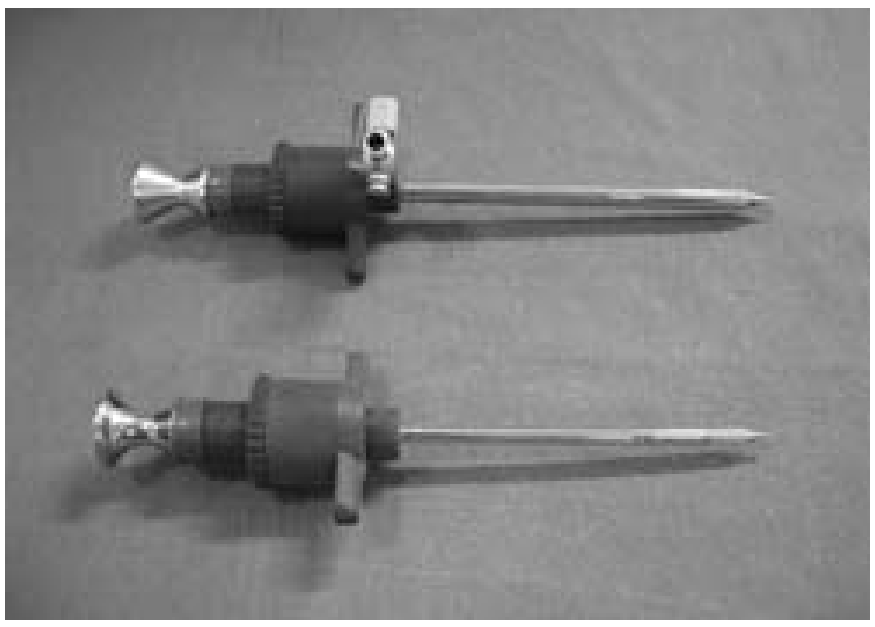

FIGURE 5. Double-entry thoracoscope. The optical tools are introduced through the 5 -mm trocar (upper tool). The second trocar (lower tool), which is narrower than the other one, is used for biopsy. 
general anaesthesia is preferred. Potentially painful procedures are those with more than two ports of entry, or procedures followed by chemical pleurodesis. Although very effective, talc poudrage is known to be painful, especially in younger patients. Painless talc poudrage can be performed with intravenous propofol and morphine in a spontaneously breathing patient.

\section{GENERAL ANAESTHESIA FOR THORACOSCOPIC PROCEDURES}

General anaesthesia is widely used for thoracoscopy procedures in the surgical literature. However, for simple diagnostic procedures with one point of entry, general anaesthesia with double lumen intubation is hardly ever necessary. The placement of a double-lumen tracheal tube requires special expertise and equipment to confirm the correct position, and is time-consuming and expensive. Therefore, these relative disadvantages should be weighed against the advantage of facilitating lung exposure.

\section{COMPLICATIONS OF THORACOSCOPY}

In four studies concerning 819 patients, no fatal case was reported [11, 20, 24, 25]. The most severe complications were as follows: subcutaneous emphysema in 39 (5\%) patients; transient cardiovascular complications in 10 (1\%) patients; empyema (two patients); fever (two patients); excessive bleeding (one patient); and air embolism (one patient). In properly selected patients (see Contraindications section), thoracoscopy under local anaesthesia is a safe procedure.

\section{CONTRAINDICATIONS OF THORACOSCOPY}

Most complications can be avoided by proper selection of patients for thoracoscopy. Patients with severe chronic obstructive pulmonary disease and consequent respiratory insufficiency, with hypoxaemia (oxygen tension $<6.65 \mathrm{kPa}$ ) and hypercapnia, will not tolerate induction of a pneumothorax without further deterioration of the gas exchange, and therefore are not suitable candidates for thoracoscopy. When there is a contralateral lung or pleural involvement, thoracoscopy is not advisable, unless general anaesthesia and tracheal intubation is used. Patients with unstable cardiovascular status should not undergo thoracoscopy. Any patient with a history of cardiovascular disease should be evaluated by the cardiologist before thoracoscopy.

Cough, fever and infection are relative contraindications for thoracoscopy. Treatment should be considered before a procedure is scheduled, and coagulation defects should be corrected before thoracoscopy.

Thoracoscopy will not be possible in the case of complete symphysis of the visceral and parietal pleura. In the case of pleural adhesions, it is possible to create a pleural space by extended thoracoscopy [26]. However, this technique should only be performed by experienced thoracoscopists.

The need for thoracoscopy should be considered carefully in severe pulmonary fibrosis as, after induction of a pneumothorax, it can be difficult to re-expand the lung due to the loss of elasticity of the pulmonary tissue. Pulmonary biopsy where honeycombing is present may result in prolonged leakage and impaired re-expansion of the lung. Pulmonary biopsy should be avoided in hydatid cysts, arteriovenous malformations and other highly vascularised lesions.

\section{PLACE OF THORACOSCOPY IN THE DIAGNOSIS OF PLEURAL EFFUSIONS}

The primary aim of diagnostic thoracoscopy is to obtain a specific diagnosis when a pleural effusion of unknown origin is present, and this occurs almost exclusively when a positive result for TB or neoplasia is obtained after examination of the pleural tissue. The probability of reaching one of these specific diagnoses through other less invasive procedures than thoracoscopy should be considered; either thoracocenthesis or needle pleural biopsy could be relied upon.

\section{Diagnostic thoracocenthesis}

Thoracocenthesis is indicated as the first step in the work-up of practically every pleural effusion of unknown origin. Total and differential cell counts, as well as biochemical study (including total proteins, lactate dehydrogenase $(\mathrm{LDH})$, glucose, adenosine deaminase (ADA)), should be carried out routinely on the pleural fluid sample. LDH can be very helpful in identifying transudative effusions whose total proteins appear elevated due to diuretic treatment. Determination of $\mathrm{pH}$ in pleural fluid is commonly accepted in algorithms dealing with management of parapneumonic pleural effusions [27], and it can be helpful in managing malignant pleural effusions too. However, its real role always has to be considered within the patient's clinical context. Transudative effusions show a $\mathrm{pH}$ ranging 7.45-7.55 (with the exception of urinothorax, which shows acidic $\mathrm{pH}$ ), but $\mathrm{pH}$ ranges between 7.30 and 7.45 in most of the exudates. A $\mathrm{pH}<7.30$ is associated with a relatively narrow spectrum of conditions (empyema, some acute tuberculous effusions, rheumatoid pleuritis and very aggressive malignant effusions). The joint presentation of both low $\mathrm{pH}$ and glucose in malignant pleural effusions is associated with marked pleural thickening and inhibition of transfer between the pleural space and the systemic circulation [28, 29]. The pleural fluid sample for $\mathrm{pH}$ is obtained and processed in the same way as arterial blood gas analysis. Cytology analysis should also be included in the initial work-up. In a prospective study, Collins and SAHN [30] showed that thoracocenthesis provides information allowing classification of the effusion in $92 \%$ of patients. However, a definite diagnosis was only obtained in $18 \%$ of the patients after initial thoracentesis in that study, thus making it necessary to perform other diagnostic techniques.

Thoracentesis can be of great value in the management of complicated parapneumonic effusions and in some specific conditions like chylothorax. A chylothorax effusion narrows down the diagnostic possibilities to only a few disorders, such as lymphoma, lymphangioleiomyomatosis and traumatic disruption of the thoracic duct. The yield of pleural fluid analysis in tuberculous or malignant pleurisy deserves a more detailed discussion.

After the first analysis, the effusion has to be classified into either transudate or exudate following the criteria of LIGHT [31]. If a definite diagnosis has not been obtained, several options must be taken into consideration, as follows. 1) If a transudate has been detected and there is a known underlying disease, no further investigations are needed. A malignancy is rarely found in effusions that are borderline between 
transudates and exudates, especially when there is a preexisting condition provoking transudative effusions [32]. In addition, malignant effusions can sometimes present transiently as transudates in some cases of carcinomatous lymphangitis [33]; this occurs mostly in pleural involvement by nonHodgkin's lymphoma, and when central airway obstruction is present. 2) When there is an exudative effusion present, a total body contrast computed tomography (CT) scan would be highly recommended; it can be of great help in detecting neoplastic pleural deposits [34].

\section{PLEURAL FLUID STUDIES IN TB}

Although the pleural fluid has the biochemical characteristics of an exudate in $\sim 100 \%$ of the cases, it is usually rich in proteins, with a predominance of lymphocytes and a paucity of mesothelial cells (at least when the effusion has become subacute or chronic); this information is of very limited value in clinical practice. The yield of a direct search for mycobacteria in the pleural fluid is very low [35], and the positivity of culture varies widely, depending upon the prevalence of TB in a specific region and on the incidence of empyemas of tuberculous origin [36].

There are a few tools available that can help in the management of patients who are suspected to have pleural TB.

\section{ADA determination in pleural fluid}

This test has been shown to be of great value in countries where the prevalence of TB is high [37], but it is seldom used in low-prevalence countries [38]. ADA is problematic in that its sensitivity is higher than its specificity, with most false positive results occurring in neoplasias (especially mesothelioma and some lymphomas) and in empyema and/or complicated parapneumonic effusions [39]. A meta-analysis that excluded empyemas found a combined sensitivity and specificity for ADA of $99 \%$ and $93 \%$, respectively [40]. However, the ADA test appears to be less useful in immunocompromised patients [41].

\section{Interferon- $\gamma$ determination in pleural fluid}

This marker appears to have better operating characteristics than ADA. According to a prospective study by VILLENA et al. [42], in 595 patients with pleural effusion, a cut-off of 3.7 IU $\cdot \mathrm{mL}^{-1}$ yielded a sensitivity of 0.98 and a specificity of 0.98. Also, the immunological status of the patient appears to have little or no influence on the results.

\section{PCR techniques for diagnosis of pleural TB}

Detection of DNA sequences that are specific to Mycobacterium tuberculosis appears to be a very promising as a rapid and specific technique for identifying pleural TB. However, several studies have found wide differences in its yield when applied to the pleural fluid. Thus, the reported sensitivity ranges between 61 and $94 \%$, and specificity varies between 78 and 100\% [43, 44]. A recent study has shown that, even in high endemic areas for TB, neither PCR nor ADA should be relied on as a single diagnostic test for pleural TB [45].

\section{PLEURAL FLUID STUDIES IN MALIGNANT PLEURAL EFFUSIONS}

The certain diagnosis of malignancy in pleural fluid can only be obtained through a positive cytology, but its yield varies widely between series, depending on the pleural neoplastic burden and the nature of the primary tumour. In agreement with SAHN and GOOD [46], the current authors have found that patients with malignant pleural effusion and low $\mathrm{pH}$ have positive cytology more frequently than those with normal $\mathrm{pH}$. Thus, among 215 cases with malignancy confirmed at thoracoscopy, a positive cytology was found in up to $78 \%$ of those with $\mathrm{pH}<7.30$, whereas it was positive in only $51 \%$ of those with a $\mathrm{pH}>7.30$. This finding was associated with greater tumour burden in the pleural cavity [47]. Although, in a meta-analysis study, HEFFNER and co-workers [48, 49] found that $\mathrm{pH}$ had little value regarding the outcome of pleurodesis and survival, the predictive value of $\mathrm{pH}$ applies differently when dealing with metastatic pleural carcinomas or mesotheliomas, as mesotheliomas usually have a lower $\mathrm{pH}$ caused by a marked pleural thickening (fig. 6) [50].

\section{Tumour markers in pleural fluid}

Although they cannot be considered as a definitive diagnosis, tumour markers can be of help in selecting patients for further investigation with more invasive techniques when they are clearly positive. In a recent study involving 416 patients, PORCEL et al. [51] found that a panel of several tumour markers in pleural fluid (CEA, CA 125, CA 15-3, and CYFRA 21-1) reached $54 \%$ sensitivity, whereas combined use of cytology and the tumour marker panel performed best in diagnosing malignant effusions (sensitivity 69\%). More than one-third of cytology-negative malignant pleural effusions could be identified by at least one marker [51].

Flow cytometry may play an interesting role in the study of pleural effusions suspected of being malignant. It can complement cytology in many cases [52], particularly in lymphocytic effusions where lymphoma is suspected $[53,54]$.

\section{PLEURAL NEEDLE BIOPSY}

Most of the current guidelines recommend the addition of a biopsy procedure when a first cytology is negative in effusions of unknown origin $[55,56]$. Percutaneous needle pleural biopsy is frequently advised in those cases [57, 58], but with the recent advances of image techniques some authors prefer CT-guided needle biopsy, which could replace blind needle biopsy in more than two-thirds of the cases [59].

Percutaneous pleural biopsy aims to obtain diagnosis only in cases where histology is crucial, such as in tuberculous pleurisy and malignancy. However, and in contrast to thoracoscopy, it does not have any therapeutic implication, and the choice between those two techniques must be based on the availability and how symptomatic the patient is [6]. Pleural needle biopsy can be easily performed on an outpatient basis [60], while thoracoscopy is more complex and requires hospitalisation of the patient.

All available biopsy needles provide a better yield in pleural TB than in malignancy, and this is due to the different degree of diffuse involvement of the parietal pleura.

\section{Pleural needle biopsy in tuberculous pleurisy}

According to a large study involving 254 patients, definitive diagnosis was based on the observation of caseous granulomas 

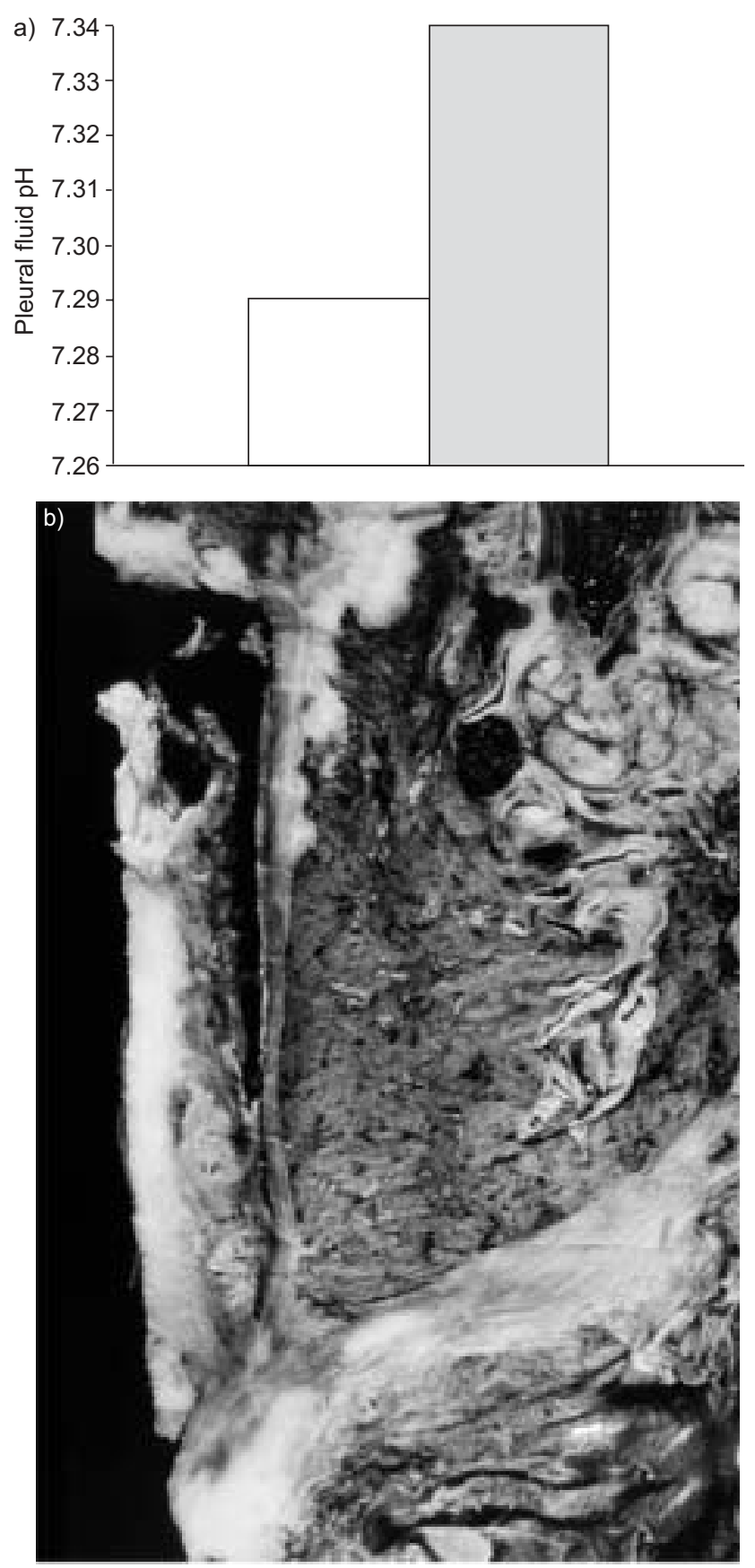

FIGURE 6. a) pH levels in the pleura of mesotheliomas ( $\square$ ) and carcinomas ( $\square$ ). b) Marked pleural thickening found in mesotheliomas (taken from RoMERO et al. [50]).

in pleural biopsy tissue samples in $79.8 \%$ of patients, the results of biopsy cultures in $11.7 \%$ of patients, and on pleural effusion cultures in the remaining $8.5 \%$ of patients [61]. Therefore, the culture of the biopsy specimen contributes significantly to the high diagnostic yield of needle biopsy in pleural TB.

The optimum number of pleural biopsy specimens to be taken for pleural TB is controversial. According to $\mathrm{KIRSCH}$ et al. [62], the yield increased significantly when six or more specimens were taken or when at least two specimens contained pleural tissue (which was not always obtained).

In a direct comparative study, DIACON et al. [63] found that the combination of pleural fluid ADA, lymphocyte-predominant cell counts and closed needle biopsy has a high diagnostic accuracy in undiagnosed exudative pleural effusions in areas with a high incidence of TB.

\section{Pleural needle biopsy in malignant effusions}

Closed pleural biopsy is less sensitive than cytology in malignant pleural effusions, even when both are repeated [64].When needle biopsy is compared with thoracoscopy, the superiority of this last technique is clear. In a prospective study involving 150 patients with malignant pleural effusion, BOUTIN et al. [65] found a positive Abrams' needle biopsy in $36 \%$, whereas thoracoscopy obtained the diagnosis in $87 \%$. In another prospective study, LODDENKEMPER et al. [66] had similar results when comparing Tru-Cut needle biopsy with thoracoscopy.

\section{Transthoracic needle aspiration/biopsy guided by image techniques}

It might be indicated in cases with a clear parietal pleura thickening or when focal areas of pleural nodularity are seen on ultrasound or CT examination. This is especially important when thoracoscopy might be difficult because of the scarcity or absence of pleural fluid, which frequently happens in malignant diffuse mesothelioma. However, obtaining pleural tissue for diagnosis is critical in those cases, and the use of a cutting (i.e. Tru-Cut) needle is then highly recommended [67].

\section{The requirement to obtain an accurate diagnosis in persistent pleural effusions}

It is sometimes stated that it is not necessary to perform thoracoscopy to obtain a correct diagnosis, because the disease is incurable and the prognosis is poor. However, HARRIs et al. [18] found that clinical management was influenced by thoracoscopy in 155 out of 182 (85\%) patients, of whom 98 (54\%) had a malignant disease. Thoracoscopic findings resulted in important changes in treatment. Further surgical or therapeutic procedures were performed or deferred in 133 (73\%) patients, and subsequent medical treatment was directly affected by thoracoscopy in $66(36 \%)$ patients, of whom 36 underwent subsequent chemotherapy and 10 underwent radiotherapy.

Thoracoscopy is the procedure of choice to differentiate between resectable and unresectable cancer if there is also pleural effusion because, in the case of pleural metastasis, the stage of disease migrates to IIIB, with a prognosis of stage IV. The development of dedicated chemotherapy for metastatic lung cancer warrants a specific diagnosis, which can not always be obtained from cytology analysis of pleural fluid. A tissue sample of the pleura is necessary to confirm the diagnosis of malignant mesothelioma versus other malignancies in many cases. Cytological analysis is diagnostic in mesothelioma in only $30 \%$ of cases. In histologically proven mesothelioma, the patient has a right to claim financial compensation from the former employer in several countries. 


\section{Should thoracoscopy always be performed in nonspecific pleuritis?}

The alternative to thoracoscopy is a wait-and-see approach. Other causes of pleuritis, such as pulmonary embolism and intra-abdominal causes, should be reconsidered and, if indicated, excluded. If the clinician expects the results to change patient management, or the patient insists on a clear definition of the underlying disease, thoracoscopy should be the next step. In the current authors' experience, many patients prefer to know the diagnosis, especially if a malignant disease is possibly the cause, by means of an endoscopic procedure under local anaesthesia, which is well tolerated and has a complication rate similar to closed pleural biopsy. In the study by HARRIS et al. [18], patient management was directly affected by thoracoscopy in $85 \%$ of patients. Pleural fluid analysis will suggest malignancy or tuberculous pleuritis in the case of elevated LDH, lymphocytosis, a combination of lymphocytic and haemorrhagic effusion [18] or an effusion which occupies more than half a hemithorax [25]. In the case of negative cytology and negative testing for TB (culture, ADA, interferon- $\gamma$, PCR), thoracoscopy is warranted.

If a large quantity of exudative pleural fluid is present in a symptomatic patient, thoracoscopy can be considered as an alternative to therapeutic thoracocenthesis because a diagnostic procedure (pleural biopsies) and a therapeutic procedure (drainage of pleural fluid, pleurodesis) can be performed in the same session.

\section{PLACE OF THORACOSCOPY IN THE MANAGEMENT OF PLEURAL EFFUSIONS}

Besides its diagnostic role, thoracoscopy is useful in certain therapeutic circumstances, in particular to prevent recurrent pleurisy. The main indication is recurrent malignant pleural effusions.

Indeed $\sim 50 \%$ of pleural exudates, which are a common clinical problem, are malignant. Although most of these patients have advanced disease with a poor prognosis, some of them may have a relatively prolonged survival. Thus, specific treatments are justifiable in an attempt to palliate symptoms. However, only a minority of patients with malignant pleural effusions benefit from suitable systemic treatment. Pulmonologists, therefore, must treat these chronic pleural effusions, as they recur rapidly and are disabling for patients.

Most patients with malignant pleural effusions (MPE) are symptomatic and their quality of life is affected. Complaints are usually dyspnoea, cough and chest pain, and treatment is focused on relieving these symptoms, taking into account that tumour does not often respond to chemotherapy. Adequate drainage, with or without pleural symphysis, is mandatory for such patients and several approaches are available to provide palliation.

\section{Therapeutic thoracentesis}

Thoracentesis is the first step in the management of the dyspnoeic patient with a malignant pleural effusion, in order to determine the effects on breathlessness and the degree and rate of recurrence. It is the treatment of choice in patients with advanced disease, poor performance status and poor expected survival. Although the value of low $\mathrm{pH}$ for the management of MPE is controversial [48, 49], it can be of help in MPE associated with metastatic carcinomas $[50,68]$. Those patients who are not good candidates for pleurodesis can be treated by outpatient thoracenteses rather than hospitalisation.

Technically, the monitoring of the pleural fluid pressure during the procedure is recommended; if intrapleural pressure is no less than $-15-20 \mathrm{cmH}_{2} \mathrm{O}$, then the removal of the fluid is not associated with adverse events $[69,70]$. However, in the absence of pleural pressure monitoring, removal of up to $1,500 \mathrm{~mL}$ is usually safe in clinical practice, providing the patient does not develop cough, dyspnoea or pain. A careful analysis of the chest radiograph is needed before thoracentesis. In the case of contralateral mediastinal shift on the chest radiograph, removal of several litres in one setting is generally safe [55]. An ipsilateral (or no controlateral) mediastinal shift can predict a potential and dramatic decrease of intrapleural pressure and, therefore, only a small amount of fluid should be removed. However, these cases usually have atelectasis or trapped lung, and it is unlikely that thoracentesis will result in relief of dyspnoea. A trapped lung can be suggested by a failure of lung re-expansion after thoracentesis, a decrease of intrapleural pressure $<-20 \mathrm{cmH}_{2} \mathrm{O}$ after fluid removal [71], and a negative pleural pressure of $19 \mathrm{cmH}_{2} \mathrm{O}$ when removing $500 \mathrm{~mL}$ of fluid [72]. A very low pleural $\mathrm{pH}(<7.20)$ is frequently associated with the presence of trapped lung [60], but a successful pleurodesis can sometimes be achieved in these patients [73].

Rapid recurrence of the effusion after relief of dyspnoea obtained by thoracentesis is an indication for further treatment. Indeed, when thoracocentesis is repeated frequently, the resulting discomfort, as well as depletion in ions, fluid and proteins, contributes to deterioration of the patient's general condition and other options must be considered.

\section{Chest tube drainage and pleurodesis}

Chest tube insertion with introduction of a sclerosing agent (chest tube-directed pleurodesis) can be considered in selected benign effusions, as well as in recurrent symptomatic malignant pleural effusions. Guidelines for the insertion of a chest drain, including training, pre-drainage risk assessment, equipment, pre-medication, technique and management of the drainage system, have recently been published [74].

Chest tube-directed pleurodesis is an option for the management of recurrent pleural effusion, but the choice between chemical pleurodesis directed by chest tube or thoracoscopy often depends upon local expertise and availability of thoracoscopy.

It is commonly performed by a large-bore tube, but similar results have been obtained using smaller-bore tubes (8-14 F) [55]. After fluid removal and lung re-expansion have been obtained, and pre-sclerosis narcotic and/or sedation has been administered, the sclerosant, diluted in $50-100 \mathrm{~mL}$ of sterile saline, is injected and the tube clamped for $\sim 1 \mathrm{~h}$. No patient rotation is necessary [75]. The chest tube is then connected to a pleural drainage unit with gentle aspiration $(<50 \mathrm{~cm}$ water suction) until the $24-\mathrm{h}$ chest tube output is $<150 \mathrm{~mL}$ [55]. However, there is no consensus concerning the daily chest output. In one study, satisfactory results were obtained by removal of the drain $2 \mathrm{~h}$ after pleurodesis [76]. In another 
study, the drain was removed the morning after the day of pleurodesis [77].

Among sclerosing agents available, talc (especially when applied through the thoracoscope, i.e. "talc poudrage") is the most cost-effective sclerosant for the management of recurrent malignant pleural effusions [78].

Although talc-slurry pleurodesis is a widely reported method of talc instillation into the pleural cavity for palliative treatment of malignant pleural effusions, the slurry preparation and talc-slurry procedure are not well defined (various volumes of saline, different amounts of talc, different chest tube sizes, various duration with clamped chest tube, level of suction after unclamping the chest tube, parameters for chest tube removal, etc.). The rationale for using this procedure is based on the simplicity of the blind bedside technique and also the lack of pulmonologists with the experience to perform thoracoscopy. Also, it would be preferred in patients who are very sick, with poor performance status, or in those with contralateral pleural involvement. However talc-slurry administration does not allow the talc to be distributed evenly over the pleural surface. Most of the talc, in fact, is eventually eliminated through the chest tube with the saline solution after the drain is unclamped (F. Rodriguez-Panadero, personal observation; fig. 7). One experimental study in dogs has shown that fibrosis and inflammation of the pleura mostly occurred in gravity-dependent areas and that pulmonary-to-costal adhesions are very rare with this technique in comparison to the talc-poudrage procedure [79]. However, another experimental study with a porcine model showed no difference between talc-slurry and talc-insufflation pleurodesis [80], as did one clinical study carried out in a small cohort [81]. Furthermore, in a randomised study in humans, MAÑES et al. [82] demonstrated that the rate of recurrence was higher in talc slurry than in poudrage application. Further clinical studies are necessary in this field.

\section{Indwelling pleural catheter}

The placement of an indwelling pleural catheter in case of malignant pleural effusion can offer an at-home management approach which is relevant for patients with terminal malignancies. This procedure allows pleurodesis in $\sim 50 \%$ of the cases with a less invasive approach than chest tube placement or thoracoscopic talc poudrage [83].

Besides the physical irritation of pleural catheter stimulating inflammatory responses, the mechanisms proposed for obtaining pleurodesis without sclerosant are: 1) the daily and continuous apposition of visceral and parietal pleuras; 2) the removal of factors interfering with this apposition; and 3) the release of inflammatory mediators. The complications of this procedure, usually performed in the bronchoscopy suite under local anaesthesia and conscious sedation, are minimal. Localised cellulitis, bacterial superinfection and incisional tumour growth occurred in a minority of patients and can be managed conservatively. However, the place of indwelling pleural catheter management in the case of free-flowing effusion is questionable, taking into account the high success rate of thoracoscopy talc poudrage with a lower complication rate [84]. Future studies with indwelling catheter incorporating catheter-directed pleurodesis might increase the success of this

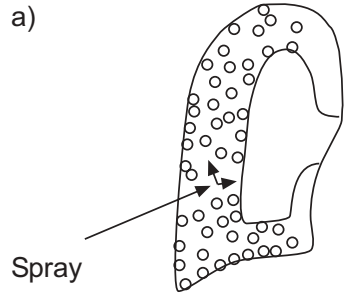

Talc poudrage b)

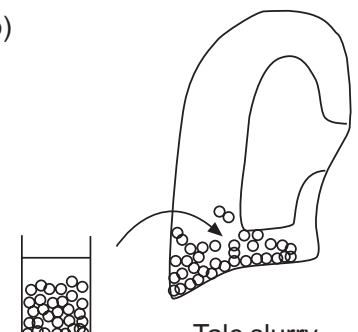

Talc slurry

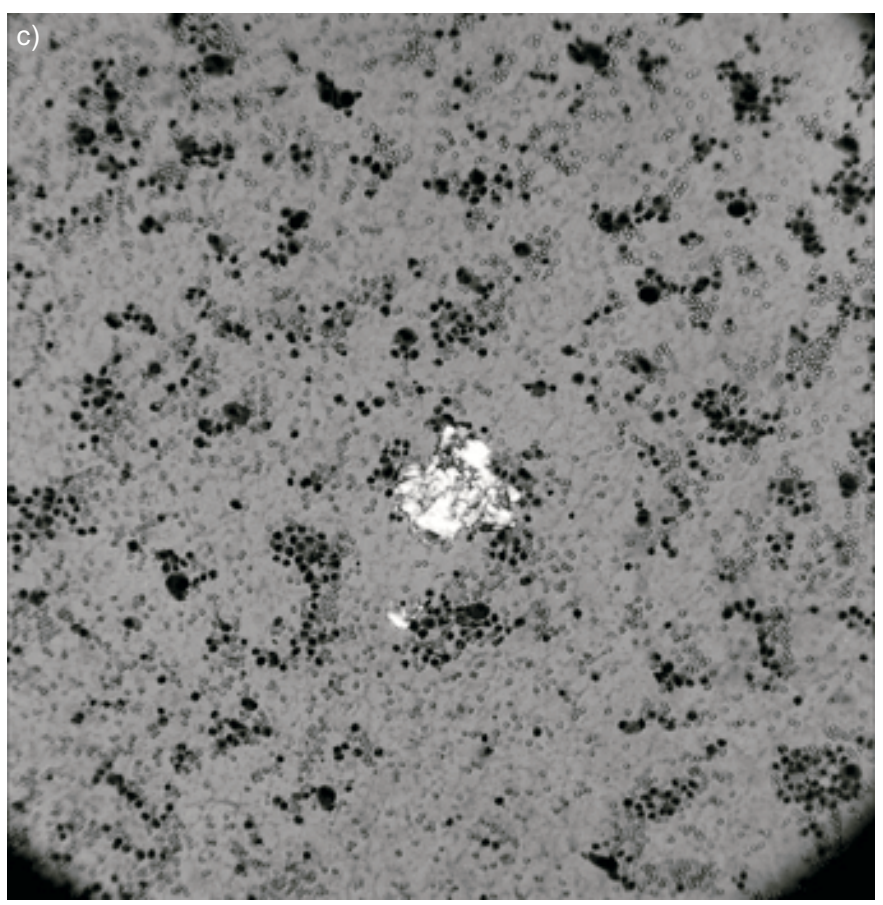

FIGURE 7. Talc poudrage (a) versus talc slurry (b). Talc is not water-soluble and, when applied in suspension as a slurry, does not distribute evenly in the pleural cavity, in contrast with talc poudrage, where dry talc is sprayed inside. Also, part of the talc instilled in slurry form comes out at the time of applying suction to the chest tube (c). Talc appears as a bright clump in the centre of the picture under polarised light on the microscope.

option. Conversely, the need for expensive supplies may temper the use of such outpatient pleural symphysis management [85].

In institutions that do not have the facilities to perform thoracoscopy, placement of an indwelling pleural catheter is obviously suitable in case of pleurodesis failure, which usually occurs soon after attempted pleurodesis as a result of suboptimal techniques or inappropriate patient selection (i.e. patients with a trapped lung or mainstem bronchial occlusion). In these cases, the placement of a permanent pleural catheter provides a convenient, effective alternative, with good symptomatic relief following catheter placement and with few major complications [86].

\section{SURGICAL MANAGEMENT}

For a palliative procedure, it is considered that thoracotomy and decortication of the lung involves major surgery with very significant morbidity and mortality, in particular after other 
options failed [87]. However, less invasive procedures, such as a thoracoscopic approach and partial parietal pleurectomy, have shown efficacy in the management of MPE for highly selected patients $[88,89]$.

Nowadays, pleuro-peritoneal shunts, initially used for the management of benign persistent pleural effusions, such as chylothorax, provide an effective and lasting solution for the management of MPE with minimal morbidity and mortality (mainly shunt occlusion and infection) [90, 91]. Prerequisites for indication of pleuro-peritoneal shunt are the failure of other methods, trapped lung, reasonable survival expectancy, and education of the patient or a family member to manage the pump. The contraindications mainly include infection of the pleural cavity or peritoneum, sepsis, congestive heart failure, and previous major abdominal surgery [92].

\section{THORACOSCOPIC TALC POUDRAGE}

Despite lack of adequate assessment of the efficacy of specific chemical agents in the literature, talc is found to be superior to other agents with $>90 \%$ success rate for talc pleurodesis in the treatment of recurrent pleural effusions [93]. Talc is an inexpensive and highly effective sclerosing agent when administered intrapleurally for symphysis. However, controversy arose about the possible role of asbestos-free talc in inducing respiratory failure due to systemic distribution of particles after intrapleural injection [94,95]. It is not clear so far whether the method of administration (slurry versus poudrage) plays a major role in the development of respiratory failure; further experimental studies are needed to answer this question. However, recent publications have pointed out the importance of the quality of talc and the size of talc particles in the safety of pleural symphysis [96-99].

Talc poudrage pleurodesis can be performed by thoracoscopy under local anaesthesia with conscious sedation or general anaesthesia. Usually the procedure is performed in patients with spontaneous breathing [84]. Several technical details should be taken into account in order to achieve good pleurodesis and avoid complications. All pleural fluid should be removed before insufflating talc. Fluid removal is easily done under visual control during thoracoscopy, as air enters the pleural cavity without insufflation. This maintains pressure equilibrium. Complete collapse of the lung allows a good view of the pleural cavity and a careful analysis of visceral and parietal pleuras; it also allows the opportunity to biopsy suspected lesions and, at the end of the procedure, permits a wide distribution of the talc on dry tissue. Usually $<5 \mathrm{~g}$ of sterile, asbestos-free, calibrated talc is recommended to obtain symphysis in patients with MPE. Thoracoscopy allows repeated pleural inspection at the end of the procedure after talc insufflation to make sure that the powder is distributed over the pleural surface. Immediate talc poudrage can be carried out in cases of macroscopic or histological evidence of malignancy and ineligibility of the patient for trials of intrapleural treatment. The safety and quality of such talc pleurodesis depends on the type of talc used [96], as well as the drainage technique and the time when pleurodesis is performed [84]. The chest tube must be inserted as low as possible in the thorax, directed posteriorly toward the costovertebral gutter, and as close to the apex as possible for optimal drainage of residual fluid, according to the Marseille school. This observation, however, has not been subject to a controlled study and is not supported by all the authors of this manuscript, who think that positioning the drain caudally would be more effective in removing any recurrent pleural fluid.

Waiting for pleurodesis is detrimental to the patient because parietal nodules and/or cancerous thickening of the visceral pleura, which increase with time, can prevent adhesion of the lung to the chest wall, this being a prerequisite for successful pleurodesis. Therefore, patients with malignant pleural effusions are good candidates for thoracoscopy and talc pleurodesis if they meet the following criteria: 1) failure or unavailability of specific treatment; 2) dyspnoea that improves after large-volume thoracentesis with subsequent and rapid recurrence of the pleural effusion; and 3) absence of trapped lung, as shown by previous thoracenteses, contrast CT or measurement of intrapleural pressures.

Thoracoscopic talc poudrage is a safe and efficient procedure for the management of patients with recurrent malignant pleural effusion. The cost of the procedure can be reduced by performing medical thoracoscopy in an endoscopy suite instead of an operating room. Despite the costs incurred by the technical procedure, it must be the treatment of choice for patients suffering this disabling disease [100].

\section{ACKNOWLEDGEMENTS}

The authors would like to thank G. Collier (Cardiff, UK) for his help with the English language.

\section{REFERENCES}

1 Jacobeus HC. Ueber die Möglichkeit die Zystoskope bei untersuchung seröser höhlungen anzuwenden. Munch Med Wochenschrift 1910; 40: 2090-2092.

2 Swierenga J, Wagenaar JPM, Bergstein PGM. The value of thoracoscopy in the treatment of diseases affecting the pleura and lung. Pneumologie 1974; 151: 11-18.

3 Brandt HJ. Diagnostik der Pleura-erkrankungen einschliesslich Thorakoskopie und Biopsie. Thoraxchirurgie 1974; 22: 371-380.

4 Boutin C, Viallat JR, Aelony Y. Practical Thoracoscopy. Berlin, Springer Verlag, 1991.

5 Janssen JP, Postmus PE, Van Mourik J, Cuesta MA. Diagnostic thoracoscopy. Diagnost Therapeut Endosc 1995; 1: 195-200.

6 Loddenkemper R. Thoracoscopy - state of the art. Eur Resp J 1998; 11: 213-221.

7 Colt HG. Thoracoscopy. A prospective study of safety and outcome. Chest 1995; 108: 324-329.

8 Noppen M, Meysman M, D'Haese J, Vincken W. Thoracoscopic splanchnicolysis for the relief of chronic pancreatitis pain. Chest 1998; 113: 528-531.

9 Janssen JP, Ramlal S, Mravunac M. The long-term followup of exudative pleural effusion after nondiagnostic thoracoscopy. J Bronchol 2004; 11: 169-174.

10 Robinson GR, Gleeson K. Diagnostic flexible fiberoptic pleuroscopy in suspected malignant pleural effusions. Chest 1995; 107: 424-429. 
11 Davidson AC, George RJ, Sheldon CD, et al. Thoracoscopy: assessment of a physician service and comparison of a flexible bronchoscope used as a thoracoscope with a rigid thoracoscope. Thorax 1988; 43: 327-332.

12 Ernst A, Hersh CP, Herth F, et al. A novel instrument for the evaluation of the pleural space. Chest 2002; 122: 1530-1534.

13 Tassi G, Marchetti G. Minithoracoscopy. A less invasive approach to thoracoscopy. Chest 2003; 124: 1975-1977.

14 Janssen JP, Thunnissen FBJM, Visser FJ. Comparison of the $2.0 \mathrm{~mm}$ and $3.5 \mathrm{~mm}$ minithoracoscopy set to standard equipment for medical thoracoscopy. Eur Respir J 2003; 22: Suppl. 45, S541.

15 Mathur P, Astoul P Boutin C. Medical thoracoscopy. Clin Chest Med 1995; 16: 479-486.

16 Canto A, Rivas J, Saumench J, et al. Points to consider when choosing a biopsy method in cases of pleurisy of unknown origin. Chest 1983; 84: 176-179.

17 Mulder DS. Pain management principles and anaesthesia techniques for thoracoscopy. Ann Thorac Surg 1993; 56: 630-632.

18 Harris RJ, Kavuru S, Metha AC, et al. The impact of thoracoscopy on the management of pleural disease. Chest 1995; 107: 845-852.

19 Aelony Y, Boutin C. Local anesthesia with thoracoscopic talc poudrage pleurodesis. Chest 1996; 110: 1126.

20 Menzies R, Charbonneau M. Thoracoscopy for the diagnosis of pleural disease. Annals Int Med 1991; 114: 271-276.

21 Oldenburg FA, Newhouse MT. Thoracoscopy. A safe accurate diagnostic procedure using the rigid thoracoscope and local anaesthesia. Chest 1979; 75: 45-50.

22 Danby CA, Adebonojo SA, Moritz DM. Video-assisted talc pleurodesis for malignant pleural effusions utilizing local anesthesia and IV sedation. Chest 1998; 113: 739-742.

23 Migliore M, Guiliano R, Aziz T, et al. Four-step local anesthesia and sedation for thoracoscopic diagnosis and management of pleural diseases. Chest 2002; 121: 2032-2035.

24 Enk B, Viskum K. Diagnostic thoracoscopy. Eur J Resp Dis 1981; 62: 344-351.

25 DeCamp PT, Mosely PW, Scott ML, et al. Diagnostic thoracoscopy. Ann Thorac Surg 1973; 16: 79-84.

26 Janssen JP, Boutin C. Extended thoracoscopy: a biopsy method to be used in case of pleural adhesions. Eur Resp J 1992; 5: 763-766.

27 Davies CW, Gleeson FV, Davies RJ. BTS guidelines for the management of pleural infection. Thorax 2003; 58: Suppl. 2, ii18-ii28.

28 Good JT Jr. Taryle DA., Sahn SA. The pathogenesis of low glucose, low pH malignant effusions. Am Rev Respir Dis 1985; 131: 737-741.

29 Rodríguez-Panadero F, López Mejías J. Low glucose and $\mathrm{pH}$ levels in malignant pleural effusions. Diagnostic significance and prognostic value in respect to pleurodesis. Am Rev Respir Dis 1989; 139: 663-667.

30 Collins TR, Sahn SA. Thoracocentesis. Clinical value, complications, technical problems, and patient experience. Chest 1987; 91: 817-822.
31 Light RW. Diagnostic principles in pleural disease. Eur Respir J 1997; 10: 476-481.

32 Assi Z, Caruso JL, Herndon J, Patz EF Jr. Cytologically proved malignant pleural effusions - distribution of transudates and exudates. Chest 1998; 113: 1302-1304.

33 Fernandez C, Martín C, Aranda I, Romero S. Malignant transient pleural transudate: a sign of early lymphatic tumoral obstruction. Respiration 2000; 67: 333-336.

34 Leung AN, Muller NL, Miller RR. CT in differential diagnosis of diffuse pleural disease. AJR Am J Roentgenol 1990; 154.3: 487-492.

35 Salazar-Lezama M, Quiroz-Rosales H, BanalesMendez JL, et al. Diagnostic methods of primary tuberculous pleural effusion in a region with high prevalence of tuberculosis. A study in Mexican population. Rev Invest Clin 1997; 49: 453-456.

36 Morehead RS. Tuberculosis of the pleura. South Med J 1998; 91: 630-636.

37 Valdes L, San Jose E, Alvarez D, et al. Diagnosis of tuberculous pleurisy using the biologic parameters adenosine deaminase, lysozyme, and interferon gamma. Chest 1993; 103: 458-465.

38 Maartens G, Bateman E. Tuberculous pleural effusions: increased culture yield with bedside inoculation of pleural fluid and poor diagnostic value of adenosine deaminase. Thorax 1991; 46: 96-99.

39 Burgess L, Maritz F, Le Roux I, et al. Use of adenosine deaminase as a diagnostic tool for tuberculous pleurisy. Thorax 1995; 50: 672-674.

40 Ena J, Valls V, Perez de Oteyza C, et al. Utilidad y limitaciones de la adenosina desaminasa en el diagnóstico de la pleuritis tuberculosa. Estudio metaanalítico [The usefulness and limitations of adenosine deaminase in the diagnosis of the tubercular pleurisy. A meta-analytical study.] Med Clin (Barc) 1990; 95: 333-335.

41 Hsu WH, Chiang CD, Huang PL. Diagnostic value of pleural adenosine deaminase in tuberculous effusions of immunocompromised hosts. J Formos Med Assoc 1993; 92: 668-670.

42 Villena V, Lopez-Encuentra A, Pozo F, et al. Interferon gamma levels in pleural fluid for the diagnosis of tuberculosis. Am J Med 2003; 115: 365-370.

43 Querol JM, Minguez J, Garcia-Sanchez E, Farga MA, Gimeno C, Garcia de Lomas J. Rapid diagnosis of pleural tuberculosis by polymerase chain reaction. Am J Respir Crit Care Med 1995; 152: 1977-1981.

44 Villena V, Rebollo MJ, Aguado JM, Galan A, Lopez Encuentra A, Palenque E. Polymerase chain reaction for the diagnosis of pleural tuberculosis in immunocompromised and immunocompetent patients. Clin Infect Dis 1998; 26: 212-221.

45 Lima DM, Colares JK, da Fonseca BA. Combined use of the polymerase chain reaction and detection of adenosine deaminase activity on pleural fluid improves the rate of diagnosis of pleural tuberculosis. Chest 2003; 124: 909-914.

46 Sahn SA, Good Jr JT. Pleural fluid $\mathrm{pH}$ in malignant effusions. Diagnostic, prognostic, and therapeutic implications. Ann Intern Med 1988; 108: 345-349. 
47 Rodríguez Panadero F. Effusions from malignancy. In: En Light RW, Lee YCG, eds. Textbook of Pleural Diseases. London, Arnold, 2003; pp. 297-309.

48 Heffner JE, Nietert PJ, Barbieri C. Pleural fluid $\mathrm{pH}$ as a predictor of pleurodesis failure. Analysis of primary data. Chest 2000; 117: 87-95.

49 Heffner JE, Nietert PJ, Barbieri C. Pleural fluid pH as a predictor of survival for patients with malignant pleural effusions. Chest 2000; 117: 79-86.

50 Romero Romero B, Sánchez Gutiérrez C, Hernández Martínez A, Martín Juan J, Castillo J, RodriguezPanadero F. Mesotheliomas have a lower pleural $\mathrm{pH}$ and longer survival than metastatic carcinomas, and similar outcome of talc pleurodesis. Am J Respir Crit Care Med 2002; 165: A33.

51 Porcel JM, Vives M, Esquerda A, Salud A, Perez B, Rodríguez-Panadero F. Use of a panel of tumor markers (carcinoembryonic antigen, cancer antigen 125, carbohidrate antigen 15-3, and cytokeratin 19 fragments) in pleural fluid for the differential diagnosis of benign and malignant effusions. Chest 2004; 126: 1757-1763.

52 Ceyhan BB, Demiralp E, Celikel T. Analysis of pleural effusions using flow cytometry. Respiration 1996; 63: 17-24.

53 Sahn SA, Heffner JE. Pleural fluid analysis. In: En Light RW, Lee YCG, eds. Textbook of Pleural Diseases. London, Arnold, 2003; pp. 191-209.

54 Kayser K, Blum S, Beyer M, Haroske G, Kunze KD, Meyer W. Routine DNA cytometry of benign and malignant pleural effusions by means of the remote quantitation server Euroquant: a prospective study. J Clin Pathol 2000; 53: 760-764.

55 Antony VB, Loddenkemper R, Astoul P, et al. Management of malignant pleural effusions. Am J Respir Crit Care Med 2000; 162: 1987-2001.

56 Antunes G, Neville E, Duffy J, Ali N. BTS guidelines for the management of malignant pleural effusions. Thorax 2003; 58: Suppl. 2, ii29-ii38.

57 Escudero Bueno C, García Clemente M, Cuesta Castro B, et al. Cytologic and bacteriologic analysis of fluid and pleural biopsy specimens with Cope's needle. Study of 414 patients. Arch Inter Med 1990; 150: 1190-1194.

58 Villena V, Lopez Encuentra A, Echave-Sustaeta J, Alvarez Martinez C, Martín Escribano P. Estudio prospectivo de 1.000 pacientes consecutivos con derrame pleural. Etiología del derrame y características de los pacientes. [Prospective study of 1,000 consecutive patients with pleural effusion. Etiology of the effusion and charcteristics of the patients.] Arch Bronconeumol 2002; 38.1: 21-26.

59 Maskell NA, Gleeson FV, Davies RJ. Standard pleural biopsy versus CT-guided cutting-needle biopsy for diagnosis of malignant disease in pleural effusions: a randomised controlled trial. Lancet 2003; 361: 1326-1330.

60 Villena V, Lopez Encuentra A, De Pablo A, EchaveSustaeta J, Alvarez Martinez C, Martín Escribano P. Diagnóstico ambulatorio de los pacientes que precisan biopsia pleural. Estudio de 100 casos consecutivos. [Ambulatory diagnosis of the patients requiring a pleural biopsy. Study of 100 consecutive cases.]. Arch Bronconeumol 1997; 33.8: 395-398.
61 Valdés L, Alvarez D, San José E, et al. Tuberculous pleurisy: a study of 254 patients. Arch Intern Med 1998; 158: 2017-2021.

62 Kirsch CM, Kroe DM, Azzi RL, Jensen WA, Kagawa FT, Wehner JH. The optimal number of pleural biopsy specimens for a diagnosis of tuberculous pleurisy. Chest 1997; 112: 702-706.

63 Diacon AH, Van de Wal BW, Wyser C, et al. Diagnostic tools in tuberculous pleurisy: a direct comparative study. Eur Respir J 2003; 22: 589-591.

64 Salyer WR, Eggleston JC, Erozan YS. Efficacy of pleural needle biopsy and pleural fluid cytopathology in the diagnosis of malignant neoplasm involving the pleura. Chest 1975; 67: 536-539.

65 Boutin C, Viallat JR, Cargnino P, Farisse P. Thoracoscopy in malignant pleural effusions. Am Rev Respir Dis 1981; 124: 588-592.

66 Loddenkemper R, Grosser H, Gabler A, Mai J, Preussler H, Brandt HJ. Prospective evaluation of biopsy methods in the diagnosis of malignant pleural effusions: intrapatient comparison between pleural fluid cytology, blind needle biopsy and thoracoscopy. Am Rev Respir Dis 1983; 127: Suppl. 4, 114.

67 Adams RF, Gleeson FV. Percutaneous image-guided cutting needle biopsy of the pleura in the diagnosis of malignant mesothelioma. Chest 2001; 120: 1798-1802.

68 Sanchez-Armengol A, Rodriguez-Panadero F. Survival and talc pleurodesis in metastatic pleural carcinoma, revisited: report of 125 cases. Chest 1993; 104: 1482-1485.

69 Light RW, Stansbury DW, Brown SE. The relationship between pleural pressures and changes in pulmonary function after therapeutic thoracentesis. Am Rev Respir Dis 1986; 133: 658-661.

70 Doelken P, Huggins JT, Pastis NJ, et al. Pleural manometry: technique and clinical implications. Chest 2004; 126: 1764-1769.

71 Villena V, Lopez-Encuentra A, Pozo F, et al. Measurement of pleural pressure during therapeutic thoracentesis. Am J Respir Crit Care Med 2000; 162: 1534-1538.

72 Lan R, Singh KL, Chuang M, et al. Elastance of the pleural space: a predictor for the outcome of pleurodesis in patients with malignant pleural effusion. Ann Intern Med 1997; 126: 768-774.

73 Aelony Y, King RR, Boutin C. Thoracoscopic talc poudrage in malignant pleural effusions. Effective pleurodesis despite low pleural pH. Chest 1998; 113: 1007-1012.

74 Laws D, Neville E, Duffy J, et al. BTS guidelines for the insertion of a chest drain. Thorax 2003; 58: Suppl. II, ii53-ii59.

75 Mager HJ, Maesen B, Verzijlbergen F, et al. Distribution of talc suspension during treatment of malignant pleural effusion with talc pleurodesis. Lung Cancer 2002; 36: 77-81.

76 Spiegler PA, Hurewitz AN, Groth ML. Rapid pleurodesis for malignant pleural effusions. Chest 2003; 123: 1895-1898.

77 Villanueva AG, Gray AW Jr, Shahian DM, Williamson WA, Beamis JF Jr. Efficacy of short term versus long term tube thoracostomy drainage before tetracycline 
pleurodesis in the treatment of malignant pleural effusions. Thorax 1994; 49: 23-25.

78 Kennedy L, Sahn SA. Talc pleurodesis for the treatment of pneumothorax and pleural effusion. Chest 1994; 106: 1215-1222.

79 Colt HG, Russack V, Chiu Y, et al. A comparison of thoracoscopic talc insufflation, slurry, and mechanical abrasion pleurodesis. Chest 1997; 111: 442-448.

80 Cohen RG, Shely WW, Thompson SE, et al. Talc pleurodesis: talc slurry versus thoracoscopic talc insufflation in a porcine model. Ann Thorac Surg 1996; 62: 1000-1002.

81 Yim AP, Chan AT, Lee TW, et al. Thoracoscopic talc insufflation versus talc slurry for symptomatic malignant pleural effusion. Ann Thorac Surg 1996; 62: 1655-1658.

82 Mañes N, Rodriguez-Panadero F, Bravo JL, Hernandez H, Alix A. Talc pleurodesis: prospective and randomized study. Clinical follow-up. Chest 2000; 118: Suppl. 4, S131.

83 Musani AL, Haas AR, Seijo L, et al. Outpatient management of malignant pleural effusions with small-bore, tunneled pleural catheters. Respiration 2004; 71: 559-566.

84 Viallat JR, Rey F, Astoul P, et al. Thoracoscopic talc poudrage pleurodesis for malignant effusions. A review of 360 cases. Chest 1996; 110: 1387-1393.

85 Ohm C, Park D, Vogen M, et al. Use of indwelling pleural catheter compared with thoracoscopic talc pleurodesis in the management of malignant pleural effusions. Am Surg 2003; 69: 198-202.

86 Pien GW, Gant MJ, Washam CL, et al. Use of an implantable pleural catheter for trapped lung syndrome in patients with malignant pleural effusion. Chest 2001; 119: 1641-1646.

87 Bernard A, de Dompsure RB, Hagry O, et al. Early and late mortality after pleurodesis for malignant pleural effusion. Ann Thorac Surg 2002; 74: 213-217.

88 Yim AP, Chung SS, Lee TW, et al. Thoracoscopic management of malignant pleural effusions. Chest 1996; 109: 1234-1238.
89 Fry WA, Khandekar JD. Parietal pleurectomy for malignant pleural effusion. Ann Surg Oncol 1995; 2: 160-164.

90 Putnam JB Jr. Malignant pleural effusions. Surg Clin North Am 2002; 82: 867-883.

91 Genc O, Petrou M, Ladas G, et al. The long-term morbidity of pleuroperitoneal shunts in the management of recurrent malignant effusions. Eur J Cardiothorac Surg 2000; 18: 143-146.

92 Schulze M, Boehle AS, Kurdow R, et al. Effective treatment of malignant pleural effusion by minimal invasive thoracic surgery: thoracoscopic talc pleurodesis and pleuroperitoneal shunts in 101 patients. Ann Thorac Surg 2001; 71: 1809-1812.

93 Walker-Renard P, Vaughan LM, Sahn SA. Chemical pleurodesis for malignant pleural effusions. Ann Intern Med 1994; 120: 56-64.

94 Light RW. Talc for pleurodesis? Chest 2002; 122: 1506-1508.

95 Werebe EC, Cazetti R, Milanez de Campos JR, et al. Systemic distribution of talc after intrapleural administration in rats. Chest 1999; 115: 190-193.

96 Fraticelli A, Robaglia-Schlupp A, Helene Riera H, et al. Distribution of calibrated talc after intrapleural administration: an experimental study in rats. Chest 2002; 122: 1737-1741.

97 Ferrer J, Villarino MA, Tura JM, et al. Talc preparation used for pleurodesis vary markedly from one preparation to another. Chest 2001; 119: 1901-1905.

98 Ferrer J, Montes JF, Villarino MA, et al. Influence of particle size on extrapleural talc dissemination after talc slurry pleurodesis. Chest 2002; 122: 1018-1027.

99 Maskell NA, Lee YC, Gleeson FV, et al. Randomized trials describing lung inflammation after pleurodesis with talc of varying particle size. Am J Respir Crit Care Med 2004; 170: 377-382.

100 Cardillo G, Faciolo F, Carbone L, et al. Long-term followup of video-assisted talc pleurodesis in malignant recurrent effusions. Eur J Cardiothorac Surg 2002; 21: 302-305. 